\title{
Simulation of Indoor Fine Suspension Particle Deposition
}

K. Q. Li ${ }^{1,2, *}$, G. C. Gong ${ }^{2}$, S. H. Zou ${ }^{1}$

${ }^{1}$ School of Energy and Safety, Hunan University of Science and Technology, Xiangtan 411201, China

${ }^{2}$ Civil Engineering College, Hunan University, Changsha 411008, China

Email: likongqinghvac@sohu.com

\begin{abstract}
In this paper, the migration and deposition of particles are simulated using the Moment Dynamic Equation (MDE). Indoor fine suspension particle depositions and particle distribution function are obtained. Gas phase flow is simulated by $v^{2}-f$ model. The simulated results of particle concentration profiles show that a uniform concentration exists in the middle region of the room with a low supplying speed. At the same time, the total number of partciels deposited is also obtained using Gradient diffusion model. Through the comparison of velocity predictions among several CFD $k-\varepsilon$ models and $v^{2}-f$ model and experimental data, it is concluded that the results obtained by $v^{2}-f$ model more accurately approximate the experimental data. So that the MDE combined $v^{2}-f$ model will gain in popularity amongst building engineers and it will gradually be adopted as an attractive alternative tool to predict contaminant particle dispersion and distribution.
\end{abstract}

\section{REFERENCES}

1. Tiana ZF, Tua JY, Yeohb GH, Yuen RKK. On the numerical study of contaminant particle concentration in indoor airflow. Building and Environment, 2006; 41: 1504-1514

2. Zhao B, Li X T, Zhang Z. Numerical Study of Particle Deposition in Two Differently Ventilated Rooms. Indoor and Built Environment, 2004; 13: 443-451

3. Einberg G, Holmberg S. Characteristics of Particles and their Behavior in Ventilation Air. International Journal of Ventilation, 2003; 2: 45-54

4. Holmberg S, Chen Q. Air flow and particle control with different ventilation systems in a classroom. Indoor Air, 2003; 13: 200-204

5. Zhao B, Wu P, Song F, Yan D, et al. Numerical Simulation of Indoor PM Distribution over the Whole Year by Zonal Model. Indoor and Built Environment, 2004; 13(6): 453-462

6. Chang T J, Hsieh Y F, Kao H M. Numerical investigation of airflow pattern and particulate matter transport in naturally ventilated multi-room buildings. Indoor Air, 2006; 16 (2): 136-152

7. Chen Q, Zhang Z. Prediction of particle transport in enclosed environment. China Particuology, $2005 ; \mathbf{3}(6): 364-372$

8. Zhang Z, Chen Q. Experimental measurements and numerical simulations of particle transport and distribution in ventilated rooms. Atmospheric Environment, 2006; 40(18): 3396-3408

9. Manceau R, et al. Turbulent heat transfer predictions using the v2-f model on unstructured meshes. Int. Journal of Heat and Fluid Flow, 2000; 21: 320-328

10. Sheldon K, Friedlander. Smoke,Dust and Haze, Fundamentals of Aerosol Dynamics(Second Edition), Oxford University Press, 2000; pp14-18,308-311

11. Mora L, Gadgil AJ, Wurtz E. Comparing zonal and CFD model predictions of isothermal indoor airflows to experimental data. Indoor Air, 2003; 13: 77-85 